\title{
The Legal Risk and Protection of the Contract of Business
}

\section{Economics}

\author{
Deng Chunlei, a \\ ${ }^{1}$ Jiangxi college of foreign studies,NanChang,330099, China \\ a dengchunlei@yeah.net
}

Keywords: Economic contract, law risk, aversion

\begin{abstract}
.
Contract, as equal civil subject of natural persons, legal persons and other organizations establishment, change or terminate civil rights and obligations between the relationships of a protocol, and expressly agreed upon a certificate of the rights and obligations regarding the trading behavior relationship between the parties. As long as there is a contract, there must be bound to the contract. Legal risk of the contract is possibility of enterprise loss in the process of production and operation by signing the contract. This possibility may be existed before the contract negotiation stage and even after the fulfillment of obligations. Prevention of legal risk of the contract, therefore, must get through the contract signing, implementation and the whole process of the ex post relief.
\end{abstract}

\section{The necessity of the prevention of legal risk contract}

Contract legal risk refers to the possibility of benefit damage or loss of one or both of the parties to a contract in the process of signing, effect, shoe line, transfer, termination and liability for breach of contract. There are theorists believe that corporate legal risk refers to because of illegal or legal or inaction leading to its expected goals of deviating, the possibility of the legal consequence of bad for business may be existed during the whole process of a contract's signing to the end. Under the condition of socialist market economy, sign and perform the contract is engaged in the production and business operation management activities and the frequent foreign business for the enterprise. In the process of signing and fulfillment of the contract, dispute may arouse due to the change of the situation, or due to the different understanding of the parties to the terms of the contract's content. When problems of determining or implement the interests become to appear, a kind of legal risk of the contract is approaching. In fact, in the process of the draft, effect, row to the end of a contract, each link has potential legal risks. In the daily economic activities, however, many enterprises have weak prevention awareness of contract due to the lack of legal knowledge and legal consciousness, and this can make the enterprise get trap into a contract legal risk. The so-called enterprise economic contract law risk refers to the final events of the contract dispute because of all sorts of change, such as the external environment change of the laws, the different social environment from previous, some dishonest acts of certain rights, lack of exercise and etc. and processed in order to solve the disputes caused by all kinds of losses or need to bear the consequences. 
Law risk is not equal to illegal risk, but all behavior lead to the legal risk is not normative. Enterprise legal risk is closely related to the enterprise's economic activities and management in the epitaxial, it refers to all possible legal risks of enterprise during the economic activities and management, including enterprise management personnel illegal crime risk, contract legal risk, infringement intellectual property legal risk, enterprise legal risk, legal risk and so on labor relations.

In numerous legal risks, economic contract law of the dispute is the most common one. This type of legal disputes often needs to waste money to solve problems in the processing, in addition, companies often need to bear the consequences of bad impact to the business itself. So, it is necessary to strengthen the management of economic contract, this is in order to kill some disputes in the bud, guarantee the legitimate rights and interests of the firm is compromised, provide guarantee to maintain its reputation and image. As the main body of market economy, the economic contract law is the intermediary putting business and market together, playing a bridge role. It can be said that any kind of behavior of the enterprise is closely linked and economic contract. So, to strengthen the management of economic contract is necessary. Only strengthening economic contract management can reduce the risk of an economic contract law, to ensure the normal operation of the enterprise, to achieve the enterprise's legitimate rights and interests are not violated, so that companies won't cause unnecessary loss. It is very beneficial to promote the survival and development of the enterprise.

\section{The reasons to causing legal risk}

(1)Imbalances and abuse of power in the management

In accordance with the trust theory, the shareholders as owners, handle property to the trustee as a client management (directors, supervisors and senior managers). Directors, supervisors and senior managers must maximize conforms to the interests of the client's wishes and the beneficiary, they can not make profit for their own self-interest, or use of the trust property for the third person. Company's directors, supervisors and senior managers, however, is easy to seek personal gain, as a kind of power tools, because of its inherent weaknesses of human nature, so as to damage the interests of the principal. As Adam Smith said, "there are very few paid manager would like to manage their money of other people's money" "All have the body of the right weight tend to abuse of power, and all powerful people are easy to abuse their power which is an experience with ages of change. Enterprise management violate duty of loyalty, improper use their power to implement certain behaviors, thus, the company and shareholders' equity suffered damage. The main reason of abusing power lies in the enterprise management personnel to give their desperate. Of course, the board of supervisors or other supervisors doesn't play their role, ineffective supervision of power is also an important reason.

(2) Business irregularities

Enterprise violate the provisions of the laws and regulations or the articles of association of the improper operation has a variety of forms. In terms of fiscal and taxation, it includes falsely capital registration, unreported income, false profits, profits and capital circulation, tax evasion, and information disclosure of listed companies and etc. In terms of production and operation, it includes production inferior products or infringing products, the violation of the provisions 
regarding the administration of safety in production, conceal production safety accidents, a large number of pollution damage to the environment, false advertising, slander others goodwill, sold by other competitors, commercial bribery, etc. In terms of labor employment, it includes the job advertisement, interviewing, hiring, use, sign labor contract, employee treatment problems. The enterprises implement the behavior of some violation of workers' rights and interests, these irregularities usually cause the damaged party activist behavior (e.g., arbitration or litigation to the enterprise) or cause sanctions by the competent department of behavior (such as the administrative department for industry and commerce, taxation departments, the relevant treatment measures of the commodity price departments).

(3) Other party's lack of credit and interest

Trade counterpart, contract fraud, breach of escaping, execute judgment refusing and etc. are the main manifestations of lacking credit. When gaining and implement of the interests of the contract have problems, a risk of loss of stems from contract interest appears. In the field of intellectual property, violating infringement of patent or trademark rights, manufacturing products, trading secret infringement, violation of technology license agreement and the implementation of market occupation and so on are inappropriate for the infringement of the interests, constituting a great threat to the development of enterprises.

\section{Prevention to the economic law risk}

(1) To strengthen the awareness of and support for legal risk

Head of enterprises realized that the awareness and management of the legal risks is a key step towards prevention of law practice. Enterprise decision-making and management level, as the core part of enterprise employees, should raise their awareness of legal risk and pay more attention to the study of legal knowledge. They should change the bad thinking of law affairs cannot bring direct economic benefits and legal affairs dispensable, strengthen the professional support of legal affairs, legal risk awareness into the enterprise culture construction, raise awareness of the legal risks of each employee, especially the senior management in the enterprise. They should have the consciousness of legal risk not only refers to the degree of the cognition of the law, the legal consciousness, but more lies in seeking all legal professional departments support self-consciousness. To strengthen the legal control is an effective mean for enterprise management to strengthen the control of the specific business and middle management, legal cost is the necessary investment cost for the enterprise, which should be clear, reasonable financial budget to ensure the benign operation of legal control link.

(2) To strengthen the construction of power restriction and internal rules and regulations

The legal risk mainly comes from enterprise interior; therefore, preventive measures should start from the enterprise itself. Enterprises should form a perfect internal control mechanism, including risk management early warning system, business operation and management system and supervision system, attaching importance to establish related implementation and supervision department, paying attention to the change of the legal policy of relevant state regulations, organization and supervising functional departments and branch offices to set up a sound system of internal control, and strengthening the position of management supervision so as to prevent the abuse of power. At the same time, establishment and improvement of internal rules and regulations is an important content of effective guard against legal risks. Enterprise must prevent beforehand, middle control and remedy according to the internal and external 
environment involved into participating market competition, the important matters involving legal risk, as well as the form of enterprise rules. For enterprise's rules and regulations, enterprise should timely make corresponding change to ensure the enterprise reasonable and lawful regulations and adapt to the needs of the market competition according to enterprise's development and the change of market competition environment.

(3) To establish prevention system of contract legal risk

“Demand investigation of 500 top enterprises' legal risk management in China "shows that corporate governance and contract management is one of the largest legal risks. CEO of China's top 500 enterprises seriously give less attention, system implementation, and budget support to legal risk prevention. So, our country enterprises' senior managers shall give enough attention to this problem. Enterprises should establish and perfect the system of contract management, first to establish contract management department (usually in corporate legal department),which is responsible for the supervision, inspection and guidance of enterprise contract signing and implementation uniformly adopting audit and management and management mode. Secondly, for specific gymnastics, enterprise should implement sound grading, panel for contract management, various business departments (such as supply and marketing, construction, technical department) and subordinate units (branches) and overseas agencies as secondary management unit, the contract shall be responsible for the department, and performance of the contract signing and report to the legal department on a regular basis about the implementation of the contract. Enterprises achieve clear management level, clear responsibilities, program specification so as to make the contract signing, implementation, evaluation and the handling of disputes are under effective control through the establishment of a sound system of contract management.

(4) Actively preventing risks of intellectual property law

On the one hand, enterprises should pay attention to protect our intellectual property. Enterprises should pay attention to protect their intellectual property through strengthening enterprise internal rules and regulations, such as setting the secrecy, signing a confidentiality agreement with technical personnel and intellectual property agreement, taking other security measures and etc. These measures can prevent the talent flow and losses for the enterprise. Enterprise shall, at the same time, react to external tort, such as the relevant administrative organ to report illegal behavior, or the court and other measures to safeguard the legitimate rights and interests of enterprises. On the other hand, the enterprise also should respect the intellectual property rights; prevent the infringement of intellectual property rights by learning and mastering of intellectual property law, so as to avoid the corresponding legal risk.

(5) Establishing a perfect management system of labor contract

At present, the existing problems in enterprise labor system mainly include following: the enterprise don't sign labor contract with workers or sign labor contract irregularly, removing labor contract not in accordance with legal procedures, don't pay society insurance for workers, security system is imperfect and etc. There are quite a number of labor dispute cases are due to enterprises making procedure just in accordance with the rules and regulations of the enterprise, the laborers refuse that kind of handling. So enterprise should establish perfect labor contract management system, use effective management means to promote the implementation of the labor contract in accordance with state laws and regulations, and improve the supporting system of labor contract and form a complete set of enterprise internal rules and regulations, 
strengthen the management of labor contract system, review and revise the existing rules and regulations.

(6) Guarantee workers to perform the corresponding responsibilities

Although not all enterprises could establish sound legal affairs work in accordance with or by reference to Measures for the Administration of Enterprise Legal Adviser, Measures for the Administration of the State-owned Enterprise Legal Adviser, but enterprise must have high quality staff engaged in legal affairs, and ensure they perform the corresponding responsibilities, such as providing legal advice and reference opinions; providing investigation report issued by books and legal evaluation;, dealing with all kinds of notarization; acting as an agent in mediation; conciliating in the civil and economic disputes; being agent of civil, criminal, economic, and administrative litigation cases and the agent of economy, labor and foreign-related cases of arbitration and etc. Ensuring enterprise staff to perform the corresponding responsibilities of legal affairs is the important guarantee to effective guard against legal risks.

\section{Summary}

Along with the continuous improvement of modern enterprise legal consciousness, more and more enterprises begin to pay attention to the prevention and control of enterprise legal risk. Legal risk management depends on vigorously support of the management level and all workers involvement of the enterprise, and constantly adjusts enterprise's legal risk prevention system along with the change of enterprises' internal and external resources so as to adapt to and satisfy the new situation for the enterprise.

\section{References}

[1]Deng Tianguo, Prevention and control of the legal risk of the enterprise[J], Chuanhua, 2007(02),12-13.

[2]Smith Adem. Anhquiry into the Nature and Cause of the WealtI[M].Chicago, 2003.

[3 ]Zhao Jiangshan, Two law risks of the 500 top enterprises facing in china. http: / / finance. sina. eom. cn / mll

[4]Meng Desijiu, Analysis of the sprits of law[M]. Beijing, The commercial press,2002.

[5]Zhu Hui, Analysis of the present law risk management of enterprises[J], Market mod ernization, 2008(09),25-29. 